\title{
The Impact of COVID-19 Pandemic on Jordanian Civil Engineers and Construction Industry
}

\author{
Dr. Khair Al-Deen Bsisu 1 \\ ${ }^{1}$ The University of Jordan, School of Engineering, Civil Engineering Department, Amman, Jordan.
} ORCID: 0000-0002-3064-9367 (Khair Al-Deen Bsisu)

\begin{abstract}
The construction industry and civil engineering contribute largely to the Jordanian GDP (gross domestic product). The lockdown due to the COVID-19 pandemic has caused all civil engineering design offices and ongoing construction projects to terminate abruptly all onsite construction work and to convert to work from home for the design engineers. This statistical study aims at finding the Jordanian engineers' perception on how they faced this lockdown, the outcomes they expect and how they see the future of civil engineering and construction industry. To achieve this, a cross-sectional study based on an online questionnaire was conducted. The results show that design civil engineers were able to work from home with reasonable efficiency while construction site civil engineers do not believe that after the lockdown is lifted the construction workers will adhere to the social distancing and to wearing essential personal protective equipment.
\end{abstract}

Keywords: COVID-19, Civil Engineering, Construction Industry, Personal Protective Equipment

\section{INTRODUCTION}

World Health Organization (WHO) has declared coronavirus disease of 2019 (COVID-19) a pandemic following the spread of this novel virus across the globe [1], [2]. The spread of COVID-19 poses an unprecedented challenge with unpredictable economic consequences [3].

Construction industry, which is a main pillar of the national economy of several Middle Eastern countries, is also facing a unique challenge due to the spread of COVID-19 in these countries, and the subsequent economic effect of a nationwide lockdown [4].

As Bill Gates has indicated in his recent article, leaders have two equally important responsibilities in any crisis; to solve the immediate problem, and to keep it from happening again [5]. Undoubtedly, construction sector has a key-role to play in saving the Jordanian national economy after the control of the spread of COVID-19. Thus, the aim of this study is to investigate the effect of this pandemic on Jordanian civil engineers, and their perception of long-term economic and legal consequences on their sector.

\section{METHODOLOGY}

\section{i. Study design}

This study is a cross-sectional investigation which was based on a self-administered online questionnaire. The study included civil engineers aging between 22 and 65 years, who are currently working either in an office job or a field job in a Jordanian construction firm whose offices and projects are all located in the Hashemite Kingdom of Jordan. The data collection took place between April $16^{\text {th }}$ and April 21 ${ }^{\text {st }}$, 2020, during which 150 engineers filled the questionnaire.

\section{ii. Questionnaire design and data collection}

The questionnaire was designed using Google Forms, which is a free electronic medium offered by Google, that has the ability to voluntarily collect information through the designed questionnaire. The questionnaire was divided into four sections. The first section was the demographics section, which collected the age, gender, field of work, the effect of COVID19 on work and on lifestyle. Based on their field of work, they either filled the office workers section or the field workers section. The final section was filled by both of the aforementioned two groups, which inquired about their perception of long-term economic and legal implications of COVID-19 pandemic on civil engineering and construction industry. No identifying information were collected throughout the questionnaire, and the collected data were used solely for statistical analysis.

\section{STATISTICAL ANALYSIS}

Microsoft Excel 2016 (Microsoft Corp., Redmond, WA, USA) was used for data recording and statistical analysis. Descriptive statistics were performed on the collected data. The age was presented as mean \pm standard deviation, while the categorical variables were all presented as number (percent) [n (\%)].

\section{RESULTS}

Overall, 150 civil engineers were enrolled in this study, of which $85(56.7 \%)$ were working in office job, while $65(43.3 \%)$ were working in field job. Of the 150 engineers, $144(96 \%)$ indicated that their work was affected by COVID-19, and 145 
$(96.7 \%)$ had their lifestyle affected by the pandemic as shown in Table 1.

Table 1. Demographic data.

\begin{tabular}{|l|l|c|}
\hline \multicolumn{2}{|l|}{ Characteristic } & Values $^{*}$ \\
\hline Age & range: [22-61] & $37.8 \pm 9.9$ \\
\hline \multirow{2}{*}{ Gender } & Male & $121(80.7)$ \\
\cline { 2 - 3 } & Female & $29(19.3)$ \\
\hline \multirow{2}{*}{ Work field } & Office job & $85(56.7)$ \\
\cline { 2 - 3 } & Field job & $65(43.3)$ \\
\hline Work affected by COVID-19** pandemic & $144(96)$ \\
\hline Lifestyle affected by COVID-19** pandemic & $145(96.7)$ \\
\hline
\end{tabular}

*values are presented as mean \pm standard deviation and $n(\%)$.

** COVID-19: coronavirus disease 2019.

I further investigated the effect of COVID-19 on the 85 office working engineers, of which $71(83.5 \%)$ are continuing to work from home due to the lockdown. Most of the engineers did not notice any change in their productivity during the pandemic $(47.1 \%)$, while $27(31.8 \%)$ complained of decreased productivity. On the other hand, only 18 (21.2\%) had an increased productivity during the outbreak. Interestingly, 44 $(51.8 \%)$ believed that working at home will substitute office work at some point as shown in Table 2.

Table 2. The effect of COVID-19 pandemic on office workingcivil engineers $(n=85)$.

\begin{tabular}{|l|l|c|}
\hline \multicolumn{2}{|l|}{ Characteristic } & Values $^{*}$ \\
\hline $\begin{array}{l}\text { Their firm adopted working at home during } \\
\text { the lockdown }\end{array}$ & $71(83.5)$ \\
\hline $\begin{array}{l}\text { Their productivity during } \\
\text { the pandemic }\end{array}$ & Increased & $18(21.2)$ \\
\cline { 2 - 3 } & Decreased & $27(31.8)$ \\
\cline { 2 - 3 } & $\begin{array}{l}\text { Stayed the } \\
\text { same }\end{array}$ & $40(47.1)$ \\
\hline $\begin{array}{l}\text { Believe working at home will substitute } \\
\text { office work }\end{array}$ & $44(51.8)$ \\
\hline
\end{tabular}

*values are presented as $n(\%)$.

Upon analyzing the effect of on field working of civil engineers, only $16(24.6 \%)$ believe that the personal protective equipment (PPE) for COVID-19 infection control will be fully available at their worksite. Only 13 (20\%) field-working engineers believed that social distancing is applicable in their work setting, while only $8(12.3 \%)$ believed that workers will adhere to safety measures and infection control policy should they be implemented as shown in Table 3 .
Table 3. The effect of COVID-19 pandemic on field working civil engineers $(n=65)$.

\begin{tabular}{|l|c|}
\hline Characteristic & Values* $^{*}$ \\
\hline $\begin{array}{l}\text { After lockdown is over, PPE** for } \\
\text { COVID-19** infection control will be fully } \\
\text { available at their worksite }\end{array}$ & $16(24.6)$ \\
\hline $\begin{array}{l}\text { Applicability to fully implicate social } \\
\text { distancing in their workplace }\end{array}$ & $13(20)$ \\
\hline $\begin{array}{l}\text { Workers will adhere to safety measures and } \\
\text { infection control policy }\end{array}$ & $8(12.3)$ \\
\hline $\begin{array}{l}\text { concerned about safety of fieldwork during the } \\
\text { pandemic }\end{array}$ & $57(87.7)$ \\
\hline $\begin{array}{l}\text { Foreign workers at their institution returned to } \\
\text { their country due to COVID-19 pandemic }\end{array}$ & $13(20)$ \\
\hline $\begin{array}{l}\text { Local workers are available to substitute } \\
\text { travelling foreign workers }\end{array}$ & $37(56.9)$ \\
\hline $\begin{array}{l}\text { Local workers are fully trained and have the } \\
\text { experience to substitute these workers }\end{array}$ & $16(24.2)$ \\
\hline *values are presented as $n$ (\%). \\
$* *$ PPE: Personal Protective Equipment \\
$* * *$ COVID-19: coronavirus disease 2019.
\end{tabular}

I further investigated civil engineers' perception of long-term effects of COVID-19 pandemic on their sector for both office and field work. Remarkably, 59 (39.3\%) believed that some engineers might lose their job as a consequence. Legal implications due to delays in projects were the concern of 47 (31.3\%) of engineers, with only $61(40.7 \%)$ being aware of the presence of a section for unforeseen events as an acceptable cause for delays in their contracts. Negative financial effect is expected by $115(76.7 \%)$, and $91(60.7 \%)$ are aware of the presence of financial aid for businesses negatively affected by COVID-19 pandemic in Jordan.

Table 4. Long-term implications of COVID-19 pandemic on civil engineering and construction industry.

\begin{tabular}{|l|l|}
\hline Characteristic & Values $^{*}$ \\
\hline $\begin{array}{l}\text { Believe some engineers might lose their job as } \\
\text { a consequence of COVID-19** pandemic }\end{array}$ & $59(39.3)$ \\
\hline $\begin{array}{l}\text { Believe there will be legal implications for } \\
\text { delays in ongoing and planned projects }\end{array}$ & $47(31.3)$ \\
\hline $\begin{array}{l}\text { Up to their knowledge, the contracts of their } \\
\text { company included a section for unforeseen } \\
\text { events as an acceptable cause for delays }\end{array}$ & $61(40.7)$ \\
\hline $\begin{array}{l}\text { They expect negative financial effect on their } \\
\text { sector due to the lockdown }\end{array}$ & $115(76.7)$ \\
\hline $\begin{array}{l}\text { They are aware of the availability of financial } \\
\text { aid for businesses negatively affected by } \\
\text { COVID-19** pandemic in Jordan }\end{array}$ & $91(60.7)$ \\
*values are presented as $n$ (\%). \\
$* *$ COVID-19: coronavirus disease 2019.
\end{tabular}




\section{DISCUSSION}

There is no doubt that most civil engineers and workers in construction industry will continue to experience the impacts of COVID-19 pandemic on their sector. To the best of our knowledge, this is the first study to investigate the impact of COVID-19 on civil engineers and construction industry.

Most of Jordanian engineers had their work affected by the pandemic. Unquestionably, the economic costs of enforcing a lockdown is enormous [6], even though this lockdown was essential for controlling the spread of COVID-19, decreasing the numbers of critical cases, and eventually reducing the number of mortality cases [7]. This puts the light on the importance of developing an integrated multidisciplinary plan for the post-lockdown period, taking into consideration all sectors, including construction industry [8].

Working from home has substituted office work in most institutions during this pandemic. Most of office-working engineers $(47.1 \%)$ did not notice any change in their productivity in the current study, $21.2 \%$ had an increased productivity, while $31.8 \%$ complained of decreased productivity. Productivity and job satisfaction for those working from home varied significantly in literature [9], [10]. This can be attributed to the multifactorial effect of organizational, job, individual and household factors on the productivity and overall satisfaction of these employees [11]. Therefore, we recommend future studies to investigate the effects of these factors in order to be able to come up with recommendations for working from home, which will ultimately help in increasing the productivity and satisfaction of these engineers.

The applicability of social distancing, enhancing sanitary measures, and providing PPE for workers and engineers during the pandemic is still understudied, especially with the worrisome lack of adequate PPE for frontline healthcare workers in developed countries [12], [13]. Moreover, with varying availability of safety tools at Jordanian construction sites and the limited availability of some PPE [14], ensuring the availability of all essential PPE and construction safety tools, as well as the application of an infection control policy must be essential in all Jordanian construction sites.

Only $40.7 \%$ of engineers in the current study were aware of the presence of a section for unforeseen events, termed as Force Majeure delays in several legal documents [15], as an acceptable cause for delays in their contracts. Importantly, with each contract mentioning Force Majeure clause differently, the applicability of the clause under the current COVID-19 pandemic will depend on the way it has been worded in their contracts [16].

COVID-19 pandemic may lead to unpredictable socioeconomic consequences, affecting the construction industry across the globe. Several studies propose that a possible economic depression might follow this pandemic [17], for which the construction and engineering sectors need to put future plans to control this undesirable economic consequence.

In conclusion, COVID-19 pandemic is a healthcare, economic and social crisis that affected all segments of the population and all economic sectors. Since construction industry is an essential tributary and one of the main pillars of the economy, actions should be taken to control the effect of this pandemic on this key sector of Jordanian economy.

\section{REFERENCES}

[1] Yashavantha Rao HC, Jayabaskaran C. The emergence of a novel coronavirus (SARS-CoV-2) disease and their neuroinvasive propensity may affect in COVID-19 patients. Journal of medical virology. 2020.

[2] Grennan D. What Is a Pandemic? Jama. 2019;321(9):910.

[3] McKibbin WJ, Fernando R. The global macroeconomic impacts of COVID-19: Seven scenarios. 2020.

[4] Inoue H, Todo YJAaS. The propagation of the economic impact through supply chains: The case of a mega-city lockdown against the spread of COVID-19. 2020.

[5] Gates Bill, Responding to Covid-19 - A Once-in-aCentury Pandemic? The New England journal of medicine. 2020.

[6] He G, Pan Y, Tanaka TJm. COVID-19, City Lockdown, and Air Pollution: Evidence from China. 2020.

[7] Walensky RP, Del Rio C. From Mitigation to Containment of the COVID-19 Pandemic: Putting the SARS-CoV-2 Genie Back in the Bottle. Jama. 2020.

[8] Karin O, Bar-On YM, Milo T, Katzir I, Mayo A, Korem $\mathrm{Y}$, et al. Adaptive cyclic exit strategies from lockdown to suppress COVID-19 and allow economic activity. 2020.

[9] Bloom NJHbr. To raise productivity, let more employees work from home. 2014;92(1/2):28-9.

[10] DuBrin AJJPR. Comparison of the job satisfaction and productivity of telecommuters versus in-house employees: A research note on work in progress. 1991;68(3_suppl):1223-34.

[11] Baker E, Avery GC, Crawford JJR, Management PiHR. Satisfaction and perceived productivity when professionals work from home. 2007.

[12] Ranney ML, Griffeth V, Jha AK. Critical Supply Shortages - The Need for Ventilators and Personal Protective Equipment during the Covid-19 Pandemic. The New England journal of medicine. 2020.

[13] Artenstein AW. In Pursuit of PPE. The New England journal of medicine. 2020.

[14] Bsisu KA-D. The Pattern of Adherence to Personal Protective Equipment (PPE) in Jordanian Small and Medium Sized Construction Sites. International Journal of Engineering Research and Technology. 2020;13(2):339-44.

[15] Wright WCJCL. Force Majeure Delays. 2006;26:33.

[16] Tax I, Law C. COVID-19 impact and Force Majeure Clauses in Construction Agreements under RERA.

[17] Estrada MAR. COVID-19: Economic Recession or Depression? 